\title{
Synthetic of Some New Fluorine Compounds Bearing 1,2,4-Triazine Moieties and the Related Hetero-Polycyclic Nitrogen Systems as Pharmacological Probes-Overview
}

\author{
Fatimah A. Al-Otaibi1,2*, Dina A. Bakhotmah' \\ ${ }^{1}$ Department of Chemistry, Faculty of Science, King Abdulaziz University, Jeddah, Saudi Arabia \\ ${ }^{2}$ Department of Chemistry, Faculty of Science, Tabuk University, Tabuk, Saudi Arabia \\ Email: ${ }^{\star}$ F-alotaibi@ut.edu.sa
}

How to cite this paper: Al-Otaibi, F.A. and Bakhotmah, D.A. (2020) Synthetic of Some New Fluorine Compounds Bearing 1,2,4- Triazine Moieties and the Related Hetero-Polycyclic Nitrogen Systems as Pharmacological Probes-Overview. International Journal of Organic Chemistry, 10, 17-38.

https://doi.org/10.4236/ijoc.2020.101002

Received: December 29, 2019

Accepted: March 15, 2020

Published: March 18, 2020

Copyright $\odot 2020$ by author(s) and Scientific Research Publishing Inc. This work is licensed under the Creative Commons Attribution International License (CC BY 4.0).

http://creativecommons.org/licenses/by/4.0/

\section{(c) (i) Open Access}

\begin{abstract}
This overview summarizes recent advanced literature surveys on the synthesis of fluorine substituted 1,2,4-triazine containing various functional groups and/or the related hetero-polycyclic nitrogen systems have been reported. In addition, physical, chemical, and medicinal properties have been evaluated. The presence of fluorinated atoms often improves these properties with an increasing electronegativity. It, also, enhances the stability of formed carbanion and it improves the hydrophobic effects which have good biological activities.
\end{abstract}

\section{Graph Abstract}
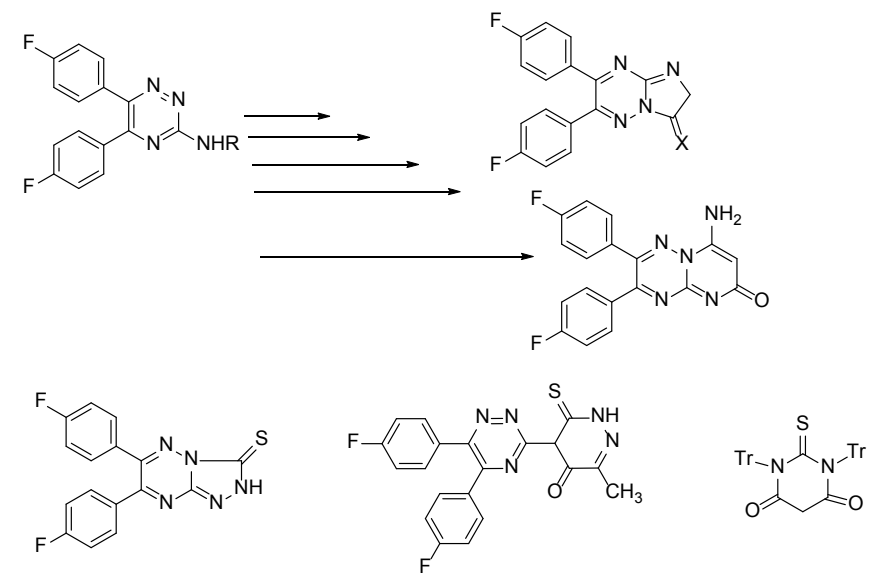

Some important anti-HIV-1 and anticancer agent 


\section{Keywords}

Design, Synthesis, Fluorinated 1,2,4-Triazino/1,2,4-Triazinone, Medicinal Properties

\section{Introduction}

Recently, fluorine substituted 1,2,4-triazine derivatives have been gathering considerable interest in various applications in pharmaceuticals activities and chemotherapy fields due to have a wide range of medicinal treatment as anti-HIV [1], anti-fungal [2], anti-cancer [3], anti-inflammatory [4], as cyclin-dependent kinases (CDK) [5] [6], anti-microbial activities [7], and antioxidant agents [8]. Most of the studies addressing synthesis and chemistry of fluorinated hetero-cyclic have been related to drug discovery research [9] [10]. It is interesting that replacing hydrogen and other functional groups with fluorine atoms can have a dramatic effect on the modulation of electronic, lipophilic, and steric parameters, all of which can critically influence both the pharmacodynamic and pharmacokinetic properties of drugs. Based upon these results, the present overview reports an important route of fluorine compounds substituted 1,2,4-triazine with the study of chemical reactivities and evaluation of the effects on the vital biological process.

\section{Synthesis of 3-Amino/Mercapto-5,6-Difluoro-Substituted- 1,2,4-Triazine}

\subsection{Synthesis}

Musator et al. [11] synthesized 3-mercapto/methyl Thia-5,6-di(4'-fluorophenyl)-1,2,4-triazine ( 1 and 2 ) from refluxing 4,4'-difluorobenzine with thiosemicarbazide in glacial acetic acid followed by methylation via treated with $\mathrm{MeI} / \mathrm{NaOH} / \mathrm{EtOH}$ to yield 2 (Scheme 1). Similarly, refluxing 4,4'-difluorobenzil with aminoguanidine bicarbonate in n-butanol yielded 3-amino-5,6-di (4'-fluorophenyl-1,2,4-triazine (3) (Scheme 1) [6].

\subsection{Reactivity}

3-Amino-5,6-difluorophenyl-1,2,4-triazines are important intermediates in the synthesis of isolated and fused heterobicyclic nitrogen systems as biological agents. Thus, Makki et al. [6] synthesized some fluorinated 1,2,4-triazine bearing other heterocyclic moieties as cyclin dependent kinases (CDK) (Scheme 2). Thus, 3-amino-6,7-di (4'-fluorophenyl)-imidazo [3,2-b] [1,2,4]triazine (4) and 6,7-di(4'-fluorophenyl)-2,3-dihydro-3-oxo-imidazo [3,2-b] [1,2,4-]triazine (5) obtained from refluxing compound 3 with chloroacetonitrile and monochloroacetic acid in DMF respectively (Scheme 2) [6].

Cyclization reactions of 3-amino-1,2,4-triazine 3 with dimethyl malonate and 
ethyl cyanoacetate in refluxing THF produced pyrimido $[3,2-b][1,2,4]$ triazin2,4-dione (6) and 4-amino-pyrimido-[3,2-b] [1,2,4]triazine-2-one (7) respectively (Scheme 3) [6].

The possible mechanism for the formation of compound $\mathbf{7}$ is in shown in Figure 1. Also, the structure of $\mathbf{7}$ deduced from mass fragmentation pattern is reported Figure 2.

Semicarbazide and thiosemicarbazide derivatives used as starting material for the building of new hetero-polycyclic nitrogen systems as pharmacological probes [12] [13]. Thus, acylation of 3 -amino-triazine $\mathbf{3}$ via treatment with ethylchloroformate in dry benzene and $\mathrm{CS}_{2} / \mathrm{KOH}$ followed by hydrazinolysis (heated at reflux with hydrazine hydrate in EtOH) produced $\mathrm{N}^{4}$-(1,2,4-triazin3'-yl) semicarbazide/thiosemicarbazide derivatives 10 and 11, respectively (Scheme 4) [6].

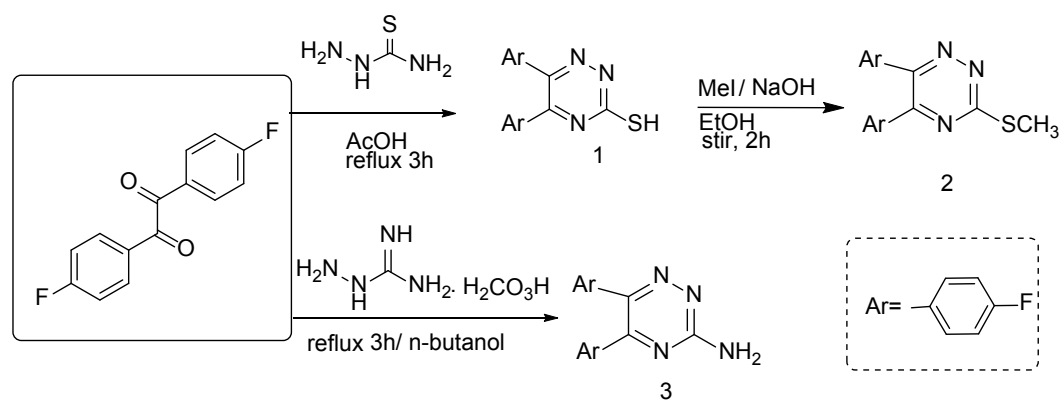

Scheme 1. Formation of compounds 1-3.

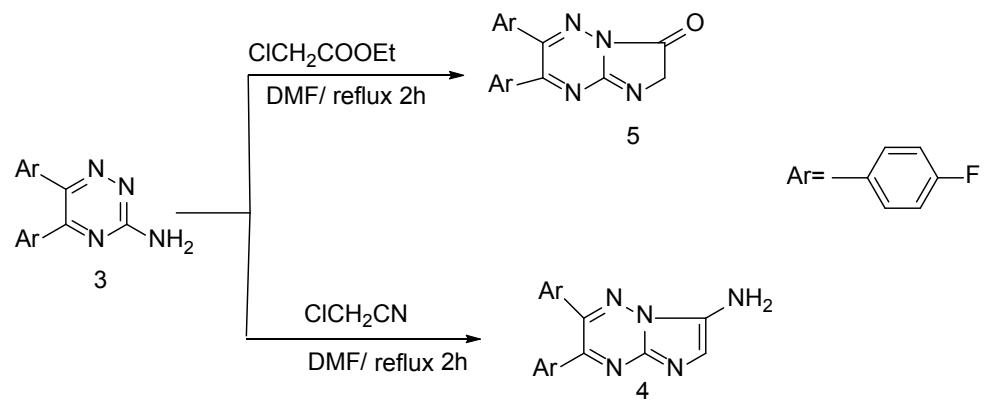

Scheme 2. Formation of compounds 4 and 5 from 3.

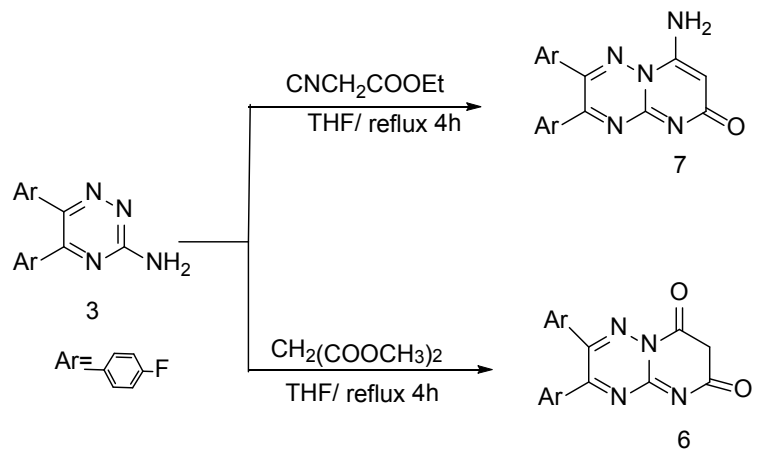

Scheme 3. Formation of compounds 6 and 7 from 3. 


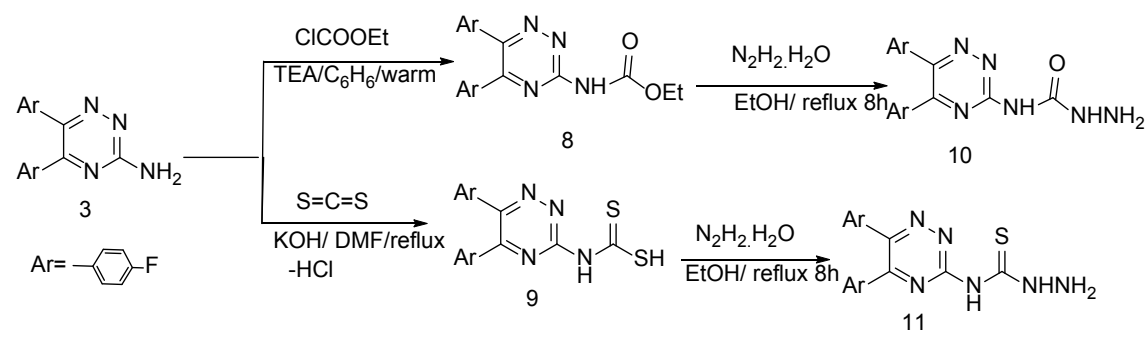

Scheme 4. Formation of compounds 8-11 from 3.<smiles></smiles>

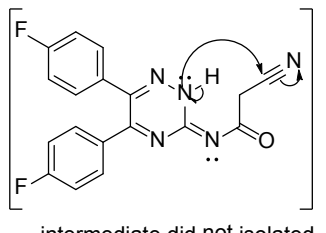

intermediate did not isolated<smiles>[3H]c1cc(=O)nc2nc(-c3ccc(F)cc3)c(-c3ccc(F)cc3)nn12</smiles>

Figure 1. Formation compound 7.<smiles>CN1C(=O)C(C)(N)C(C)(N)C(=O)N=C1N=C(c1ccc(F)cc1)c1ccc(F)cc1</smiles>

7, $\mathrm{M}^{+} 351(8.18)$

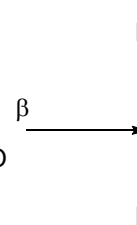

今

$307(28.13)$

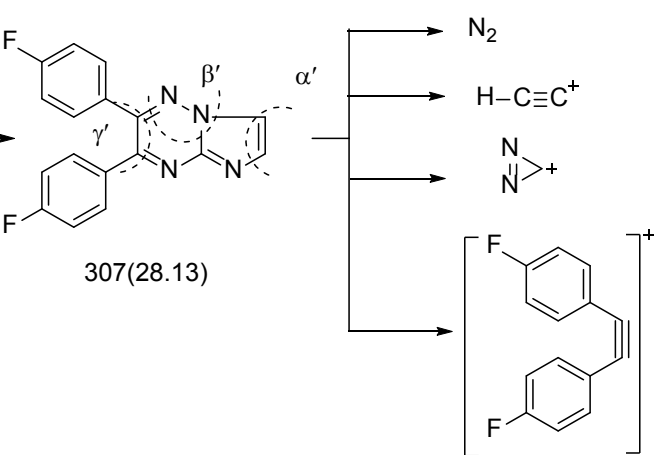

214(100)

Figure 2. Mass fragmentation pattern of compound 7.

Under the experimental conditions, the ring closure reaction of compound 10 by refluxing with triethyl orthoformate, $\mathrm{CS}_{2}$ (DMF) and sodium pyruvate (aq. $\mathrm{NaOH}$ ) yielded the 1,2,4-triazolone 12 and1,2,4-triazolthion 13 and the 6-azauracile 14, respectively (Scheme 5) [6].

The structure of compound $\mathbf{1 3}$ was deduced using the mass fragmentation pattern (Figure 3) [6].

Similarly, hetero-cyclization of compound 11 under the last same conditions and reagents lead to the direct formation of 1,2,4-triazol-3-thions 15 and 16 and/or 3-thioxo-4-[5,6-di(4'-fluoro-phenyl) 1,2,4-triazin-3'-yl]-6-methyl-1,2,4-triazin-5-one (17), respectively (Scheme 6) [6].

On other hand, fully fluorinated thiobarbituric acids bearing 1,2,4-triazine moieties 19 obtained from the interaction between compound 3 with 9 in ref- 
luxing EtOH to give N, N'-disubstituted thiourea 18, which upon ring closure reactions with malonic acid in refluxing glacial acetic acid yielded the target 19 (Scheme 7) [8].

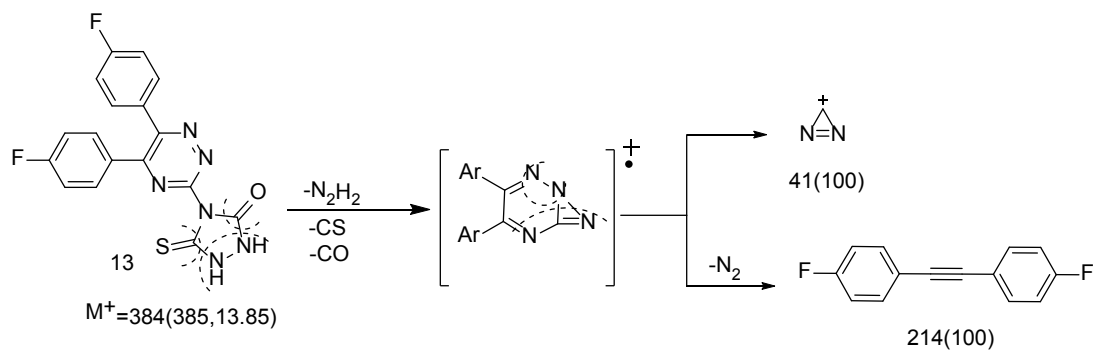

Figure 3. Mass fragmentation pattern of compound 13.

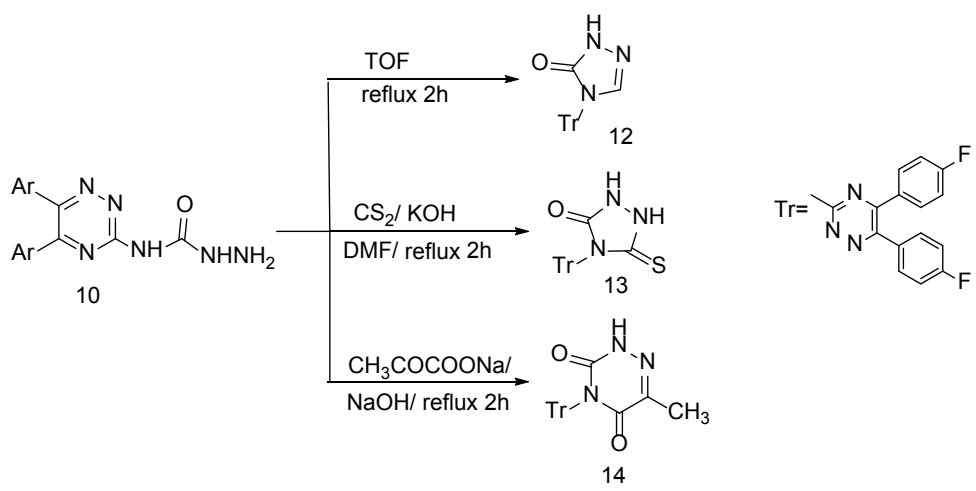

Scheme 5. Formation of compounds 12-14 from 10.

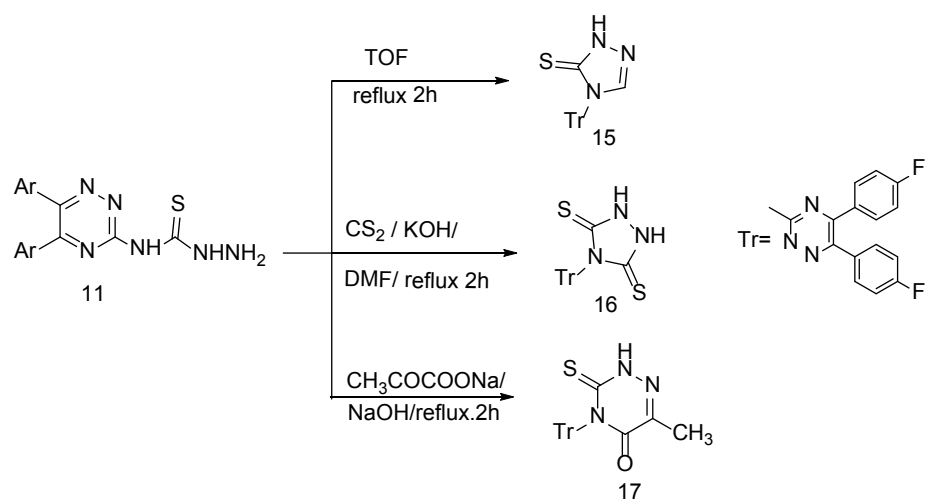

Scheme 6. Formation of compounds 15-17 from 11.

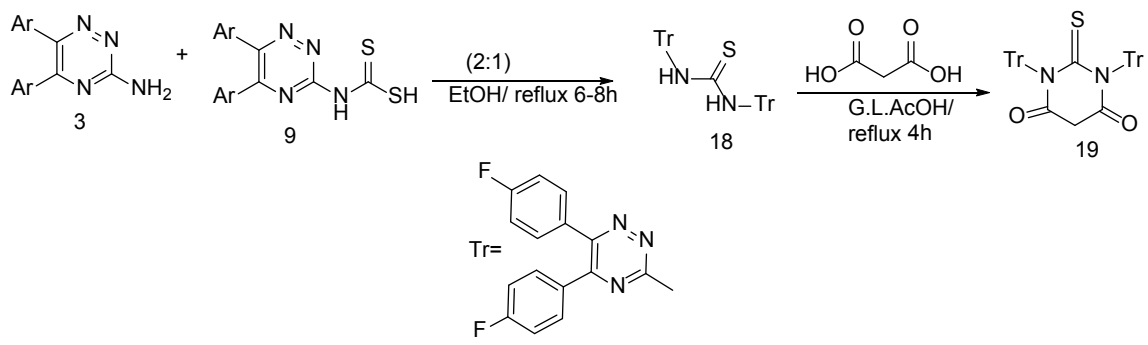

Scheme 7. Formation of compounds 18 and 19. 
The CDK2 inhibitory activity of the compounds 3-9 evaluated in comparison with olomoucine as standard according the reported method [14], where the highly inhibitor effects increase in the order $11>13>16>17>3$. The compound 16 exhibit a good effect toward the tumor cells damage as the olomoucine. Also, the in vitro antitumor testing of the highly active compounds evaluated according the reported method [15] under different concentration. A sulforhodamine B (SRB) protein assay was used to estimate cell viability or growth by determining $\mathrm{GI}_{50}$, TGI, and $\mathrm{LIC}_{50}$. Compound 11 showed the anticancer activity against non-small cell lung, renal, and breast cancer cell, while compound 13 exhibit anti-cancer of type leukemia and breast cancer cell, compound 16 showed anti-cancer activity against non-small cell lung cancer, finally, compound 17 exhibit anti-cancer of type breast cancer [6].

\section{Synthesis of Fluorine Compounds Substituted Fused Hetero-Bicyclic Nitrogen Systems Containing 1,2,4-Triazines}

\subsection{Synthesis}

Due to a highly resistance of microorganisms towards the anti-biotic uses, Aqlan et al. [16] synthesized new fluorine substituted pyrimido-1,2,4-triazinones as plant protection of wheat grain from fungi infection by using 2-hydrazino-4(4'-fluorophenyl)-6-oxo-pyrimidine-5-carbonitrile (20) as a nucleophilic reagents attack of various functional reagents as electrophilic to produce the new fluorine compounds.

Cyclocondensation of 2-hydrazino-pyrimidinoe 20 with 1,2-bicarbonyl compounds such as sodium pyruvate/aq. $\mathrm{NaOH}$ or diethyl oxalate (THF) under refluxing $2 \mathrm{~h}$ produced 8-(4'-fluorophenyl)-7-cyano-3-methyl-pyrimido [3,2-c] [1,2,4]triazin-4,6-dione (21) and 8-(4'-fluorophenyl) -7-cyano-1,2,3,4-tetra hydro pyrimido-[3,2-c] [1,2,4]triazin-3,4,6-trione (22), respectively (Scheme 8) [16]. The interaction between compound 20 with (E)4-aryl-2-oxo-but-3-eneoic acid in refluxing aq. $\mathrm{NaOH}$, yielded 8-(4'-fluorophenyl)-7-cyano-3-styryl-1H-pyrimido [3,2-c] [1,2,4]triazin-4,6-diones (23) and not 24 (Scheme 9) [16].

Formal structure of compound 23 deduced from spectral measurements. Mass spectrometric study were recorded a molecular ion peak that the base peak Figure 4 [16].

Due to the important properties of fluorinated heterocyclic substituted indole moieties for their applications [17] [18]. Thus, interaction between 2-hydrazinopyrimidinone 20 and isatin in refluxing aq. $\mathrm{NaOH}$ or DMF yielded 8-(4'-fluorophenyl)-7-cyano-3-(2'-aminophenyl)-1H-pyrimido [3,2-c] [1,2,4]triazine-4,6-dione (25) or 11-(4'-fluorophenyl)-10-cyano-1H-pyrimido [3,2-c] [1,2,4]triazino-[6,5b] indole(26), respectively (Scheme 10) [16].

A regioselective hetero-cyclization of 2-hydrazino-pyrimidinone 20 towards $\alpha$-active electrophilic agents [19] [20] as monochloroacetic acid (aq. $\mathrm{NaOH}$ ) and chloroacetyl chloride (DMF) under warming leads to the direct formation of fluorinate pyrimido-triazinones 27 and/or 28 , respectively (Scheme 11). Both 
the compound 27 and 28 are considered an isomeric structure [16].

\subsection{Reactivity}

The mass fragmentation pattern of compounds 21 and 26 give us a good indication about their stability Figure 5 and Figure 6 [16], were the base peaks in these compounds are 95 (4-fluorophenyl) ions.

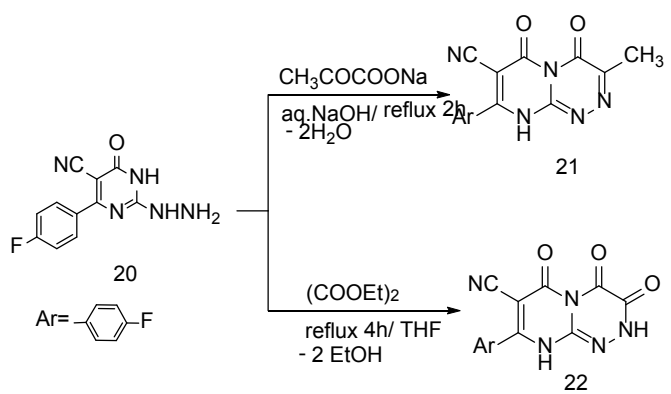

Scheme 8. Formation of compounds 12 and 22 from 20.

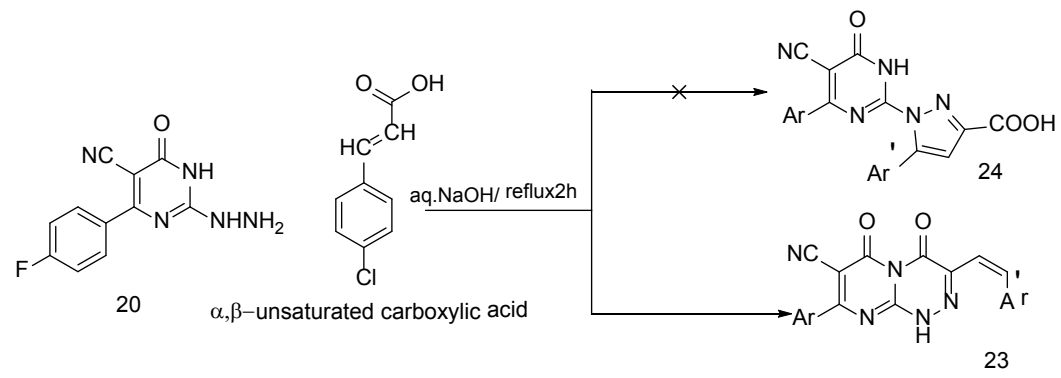

$\mathrm{Ar}=-1-\mathrm{F} \quad \mathrm{Ar}^{\prime}=-\mathrm{Cl}$

Scheme 9. Formation of compound 23.

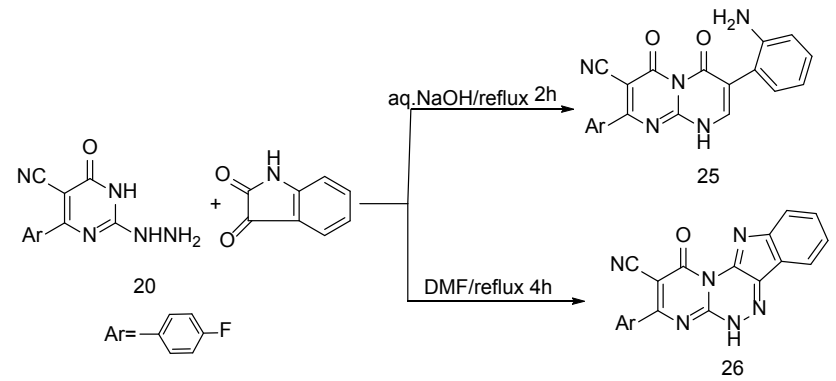

Scheme 10. Formation of compounds 25 and 26 from 20.
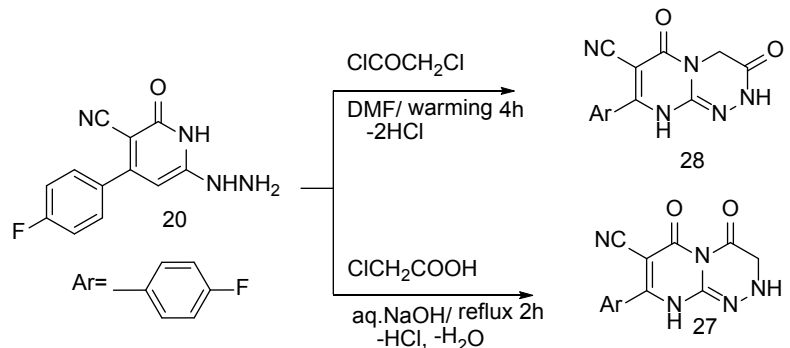

Scheme 11. Formation of compounds 27, 28 from 20. 


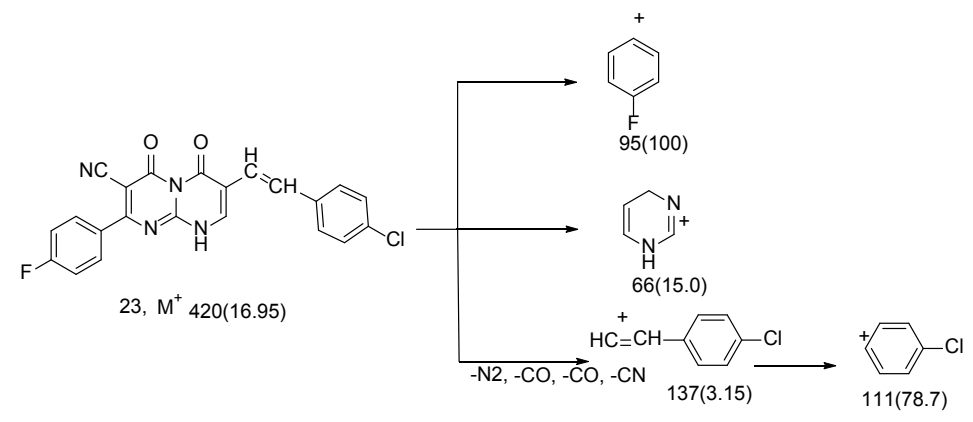

Figure 4. Mass fragmentation pattern of 23.

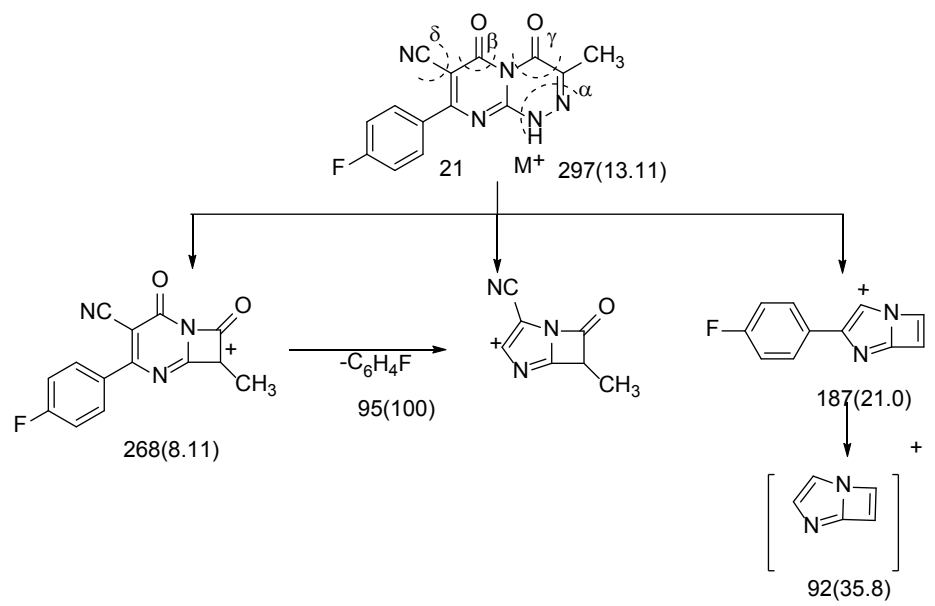

Figure 5. Mass fragmentation pattern of 21.

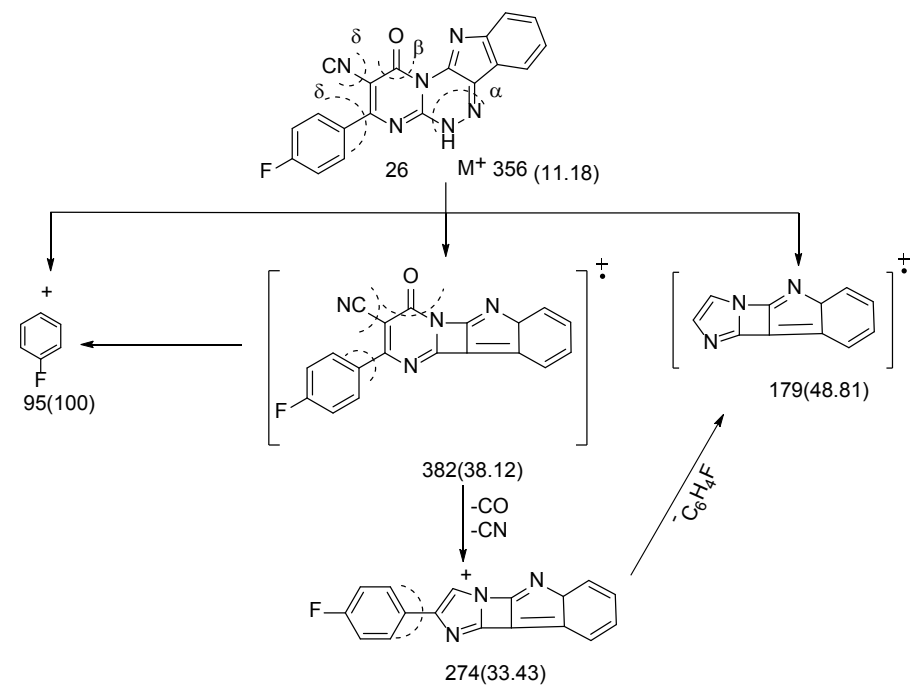

Figure 6. Mass fragmentation pattern of 26.

The presence of a free amino group in the structure of $\mathbf{2 5}$ was established from Fluoroacylation by warming with hexafluoro-acetic anhydride (DMF) or fluoro-aroylation by warming with 4-fluoro-benzoyl chloride (DMF), afforded the $\mathrm{N}$-(trifluoroacetamido) 29 or $\mathrm{N}$-(4'-fluoro benzamido) derivatives $\mathbf{3 0}$, respectively (Scheme 12) [16]. 
Oxidation of 27 and 28 via refluxing with $\mathrm{Fe}_{2}\left(\mathrm{SO}_{4} / \mathrm{CH}_{3} \mathrm{OH}\right.$ yielded the tautomeric structures 31 and 32, respectively (Scheme 13) [16].

The obtained compounds 21-32 evaluated both in vitro and in vivo of antifungal activity by inhibition of fungal mycelial growth of Alternaria alterata, helimen thosporium sativum and Fusarium moniliform according the reported methods [21] [22] [23], where the compounds 23, 29 and 30 exhibit a high fungal toxicity activity. Prevention of blue mold development indicate the action of these compounds on the decay control on rind discs, were only the compounds 21 and 23 gave a good control at concentration at $500 \mathrm{mg} / \mathrm{cm}^{-1}$ against Alternaria alterata. The best germination $(80 \%-90 \%)$ was achieved by treating the seeds with a solution containing $1000 \mathrm{mg} / \mathrm{ml}$ of the compound 23 followed by 29 under the same concentration (59\% - 70\% germination) [16]. Similarly, the design, synthesis and molluscicidal activity of new phosphorus compounds bearing fluorine substituted 1,2,4-triazolo [5,1-c] [1,2,4]triazine derivative reported by Abdel-Rahman et al. [24].

\subsection{Synthesis}

Refluxing 3-hydrazino-4-(4'-fluoro phenyl)-5-(pyridine-4'-yl)-1,2,4-triazole (33) with isatin in aq. $\mathrm{NaOH}$ or with diethyl oxalate in THF produced 3-(2-aminophenyl)-8-(4'-fluorophenyl)-7-(pyridine-4'-yl)-1,2,4-triazol [5,1-c] [1,2,4]triazin$4(8 \mathrm{H})$-one (34) or 8-(4'-fluorophenyl)-7-(pyridine-4'-yl)-2,4-dihyro [1,2,4]-triazol [5,1-c] [1,2,4]triazin-3,4-dione(35), respectively (Scheme 14) [24].

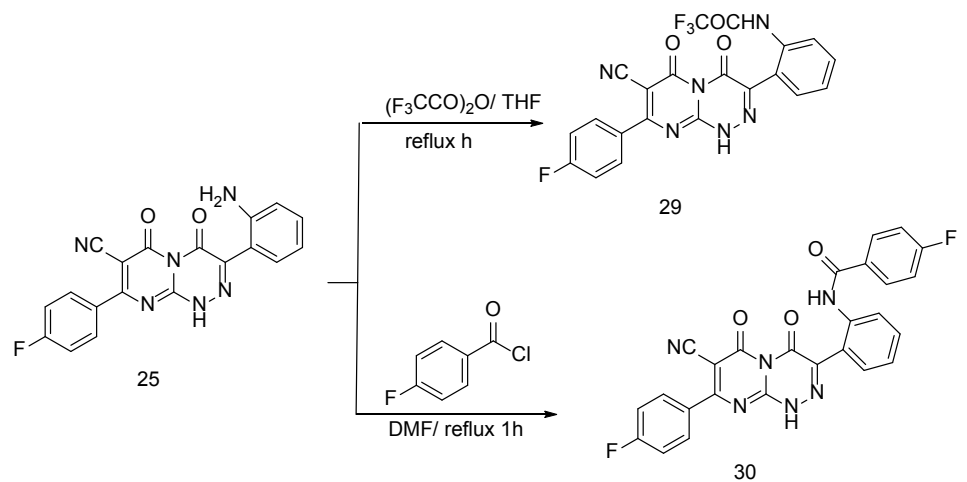

Scheme 12. Formation of compounds 29 and 30 from 25.

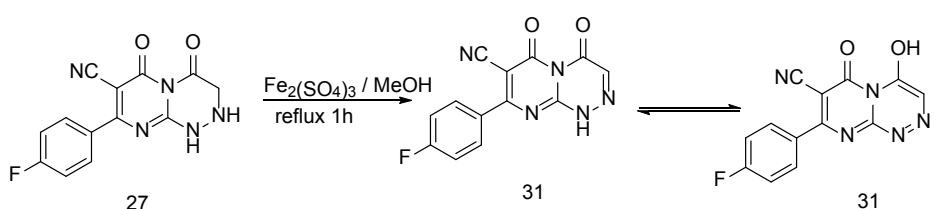

27

31

31

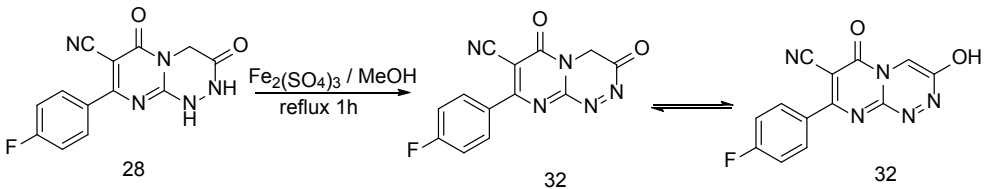

Scheme 13. Oxidation of compounds 27 and 28. 


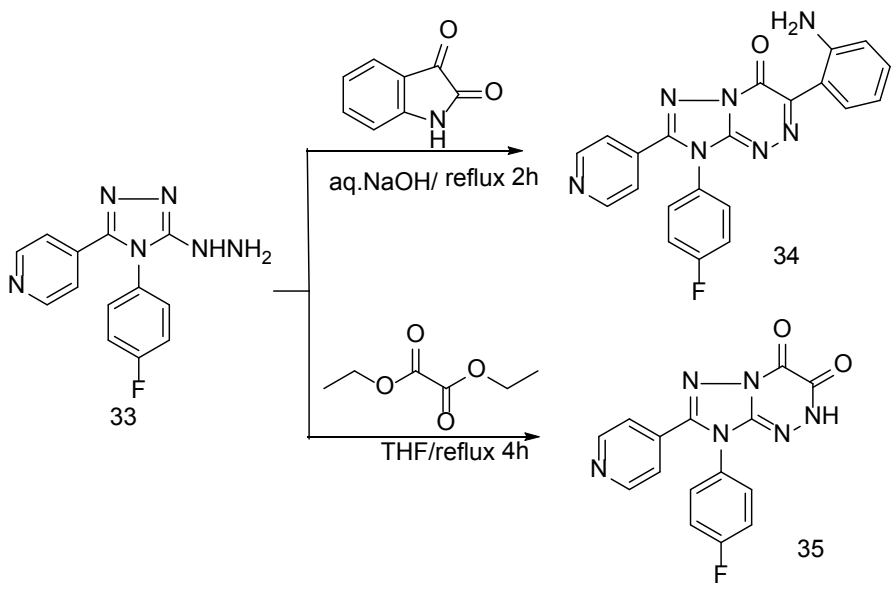

Scheme 14. Formation of compounds 34 and 35 from 33.

\subsection{Reactivity}

Phosphorylation of both compounds 34 and 35 by warming with chloro-diphenyl phosphate in the presence the DMF afforded the $\mathrm{N}$-(diphenyl phosphiteamino) 36 and 37, respectively (Scheme 15) [24].

The stability of compound $\mathbf{3 7}$ is indicated by the mass fragmentation pattern in Figure 7.

Compound 36 and 37 can be used as molluscicidal agents against the snails which cause the disease of Bilharziasis according via the reported method [24], where the compound $\mathbf{3 7}$ exhibit higher activity than $\mathbf{3 6}$ in comparison with Bayluscids as a standard control (Table 1) [24].

\section{Synthesis of Fluorine Substituted Pyrazolo [4,3-e] $[1,2,4]$ Triazines as Purine Analogues as (Condensed Systems)}

\subsection{Synthesis}

Fluoroacylation of 4-aminoantipyrine (38) by warming with trifluoroacetic acid in THF yielded the N-trifluoroacetyl derivative 39 , which upon heterocyclization by refluxing with hydrazine hydrate in abs.EtOH produced 2,3-dimethyl-1phenyl-4H-5-trifluoromethyl-pyrazolo [4,3-e] [1,2,4] triazine (40), aroylation of 38 by warming with 4 -fluorobenzoyl chloride in DMF produce the $\mathrm{N}$-aryl amino 41 . Ring closure reaction of 41 with aryl hydrazine in refluxing DMF gave 2,3-dimethyl5-(4'-fluorophenyl)-6-(4'chlorophenyl)1-phenyl-pyrazolo [4,3-e] [1,2,4] triazine (42) (Scheme 16) [25]. Similarly, cyclocondensation of $\mathbf{3 8}$ with acid hydrazide in refluxing DMF yielded the pyrazolo-triazine 43, which on fluoroacylation produced N-trifluoroacetyl 44 (Scheme 16). The formation of $\mathbf{4 2}$ from 38 is shown in (Figure 8). Also, mass spectroscopy study of compound 44, were shown the molecular ion peak at low \% with a base peak at $\mathrm{m} / \mathrm{z} 198(100 \%)$ attributes $\mathrm{C}_{12} \mathrm{H}_{12} \mathrm{~N}_{3}^{+}$as Figure 9 [25]. 
Table 1. The mortality of sanils at different concentrations.

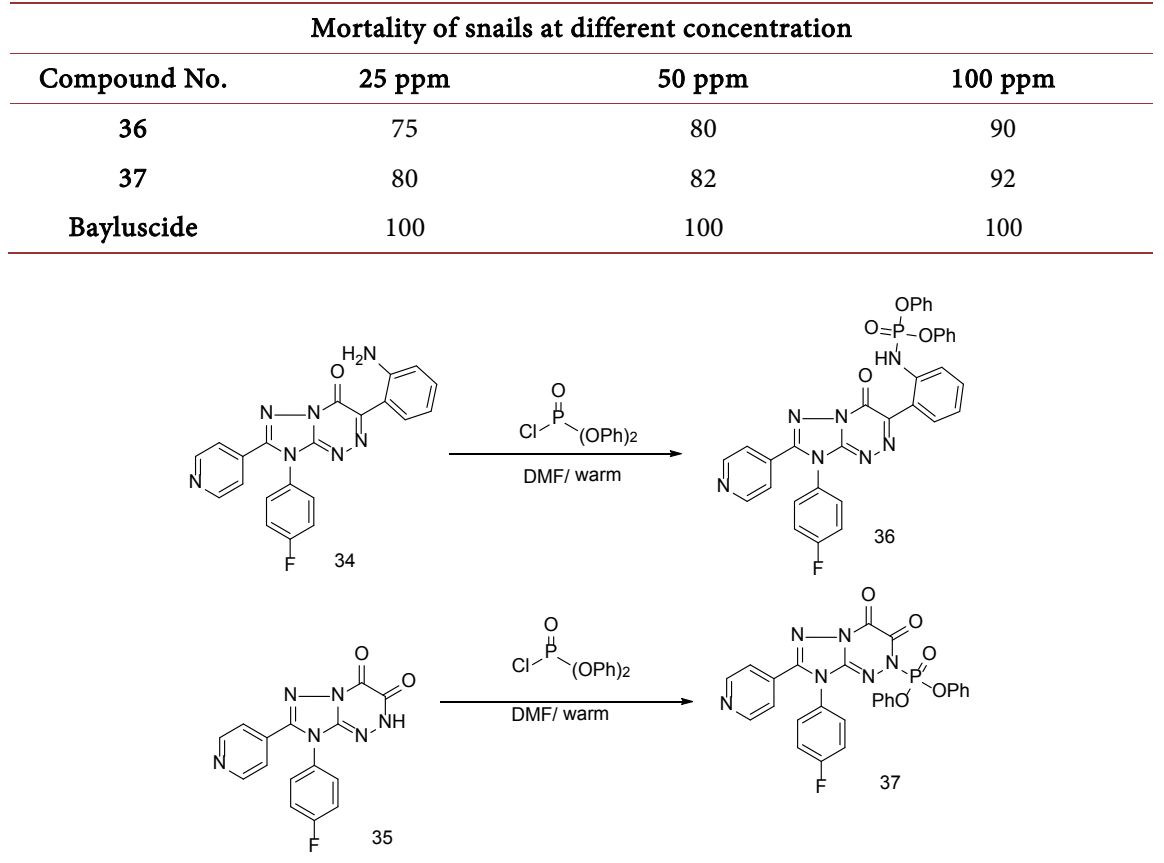

Scheme 15. Formation of compounds 36 and 37.
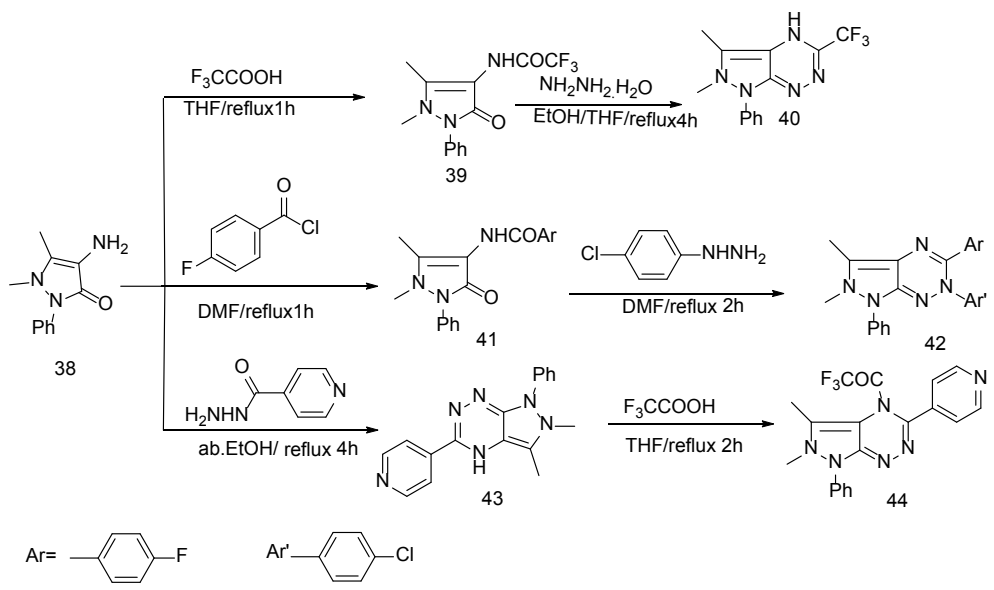

Scheme 16. Formation of compounds 39-44 from 38.

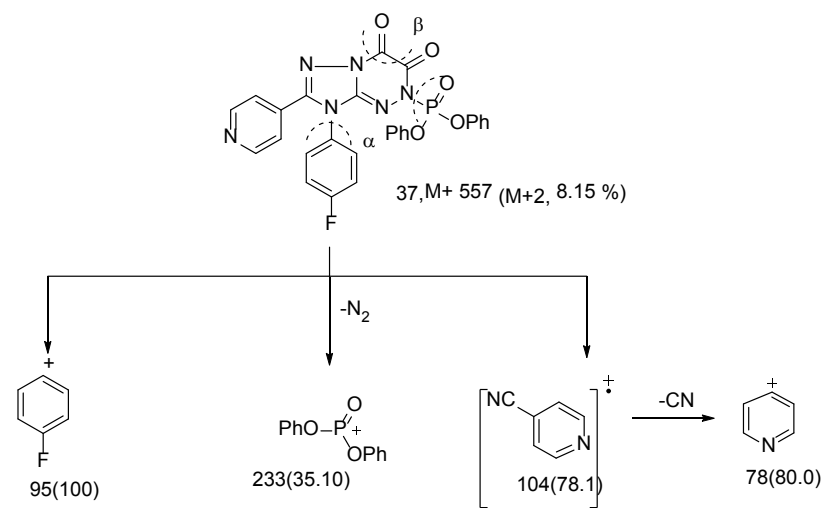

Figure 7. Mass fragmentation pattern of 37. 


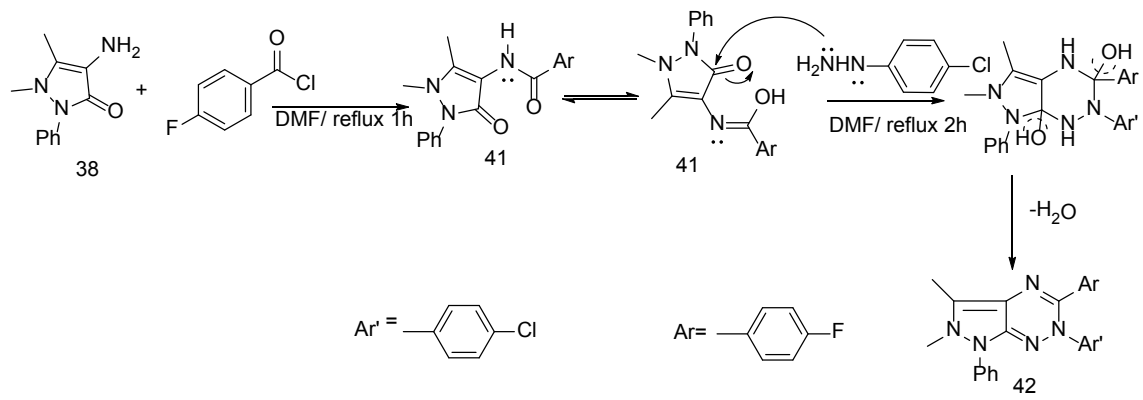

Figure 8. Formation of compound 42 from 38.

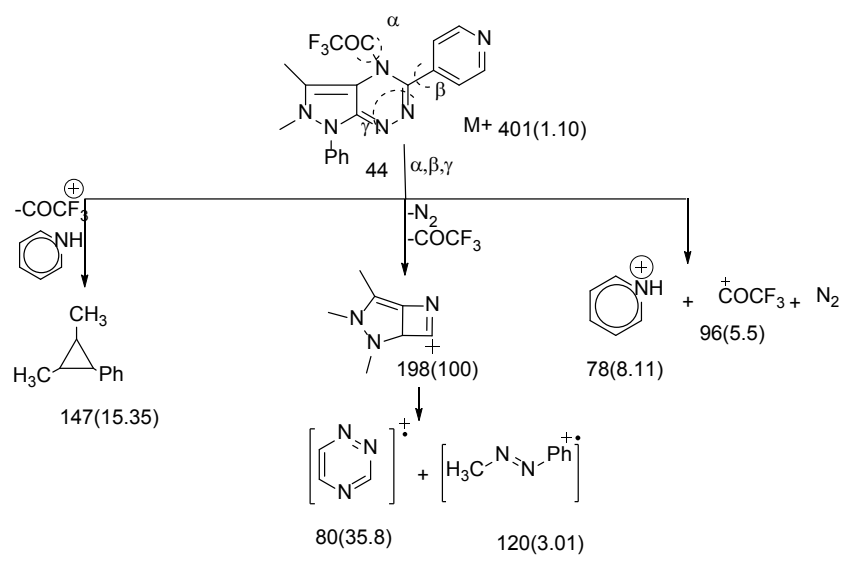

Figure 9. Mass fragmentation pattern of compound 44.

The ddition of aryl isothiocyanate to compound 38 in warming DMF, yielded the $\mathrm{N}, \mathrm{N}$-disubstituted thiourene 45 , which upon hydrazinolysis in refluxing ethanol, produced 2,3-dimethyl-1-phenyl-4H-5-aryl amino-pyrazolo [4,3-e] $[1,2,4]$ triazine (46), while addition of $\mathrm{CS}_{2}$ in aq. $\mathrm{KOH}$ to 38 , followed by hydrazinolysis gave $\mathrm{N}^{4}$ (substituted)thiosemicarbazide 47 . Self-condensation of $\mathbf{4 7}$ lead to the formation 2,3-dimethyl-1-phenyl-4,5,5,6-tetrahydro-5-thioxo-pyrazolo [4,3-e] [1,2,4] triazine (48) Figure 10. Compound 48 also obtained [25] directly from refluxing 38 with thiosemicarbazide in acetic acid (Scheme 17). Formation of compound $\mathbf{4 8}$ from $\mathbf{3 8}$ may be tack's place via the addition reaction between an amino-group of $\mathbf{3 8}$ and highly positive Carbone atom of $\mathrm{CS}_{2}$ followed by hydrazinolysis $\mathbf{4 7}$ and finally cyclocondensation via carbonyl group as shown in Figure 10.

Also, 2,3-dimethyl-1-phenyl-4,5,5,6-5-tetrahydro-5-oxo-pyrazolo $\quad[4,3-c]$ $[1,2,4]$-triazine (50) was produced from treatment of compound 38 with ethylchloroformate in worming $\mathrm{C}_{6} \mathrm{H}_{6}$-TEA followed by hydrazinolysis in refluxing THF (Scheme 18) [25].

It is interesting that, addition compound $\mathbf{3 8}$ as nucleophilic agents to $\pi$-acceptor electrophilic as cyanamide in refluxing EtOH-piperidine as catalysis yielded the guanidine derivative $\mathbf{5 2}$, which on hydrazinolysis in DMF afforded 5-amino-2,3-dimethyl-1-phenyl-4H-pyrazolo [4,3-e] [1,2,4]triazine (53). Compound 53, also isolated from addition of $\mathrm{H}_{2} \mathrm{NCN}$ into compound 38 to give the amino-nitrile 54, followed by hydrazinolysis (Scheme 19) [25]. 


\subsection{Reactivities}

Fluoroacylation of compounds $\mathbf{4 3}, 50$ and 53 by warming with trifluoroacetic acid in THF lead to the isolation of $N$-trifluoroacetyl derivatives 44,51 , and 55 , respectively (Scheme 20) [25].

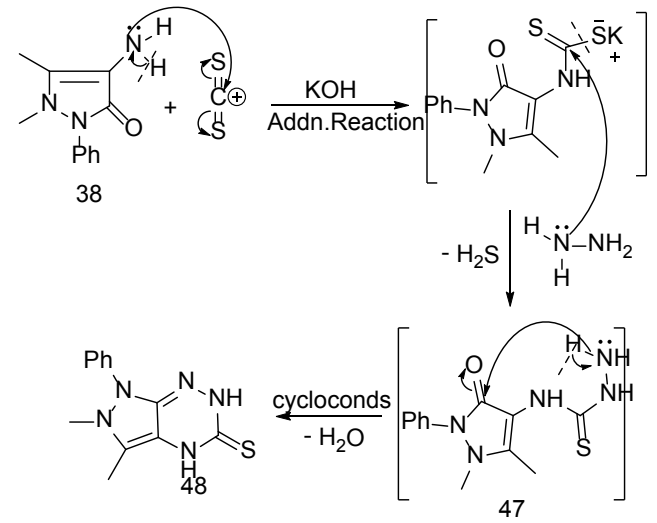

Figure 10. Formation of compound 48 from 38.

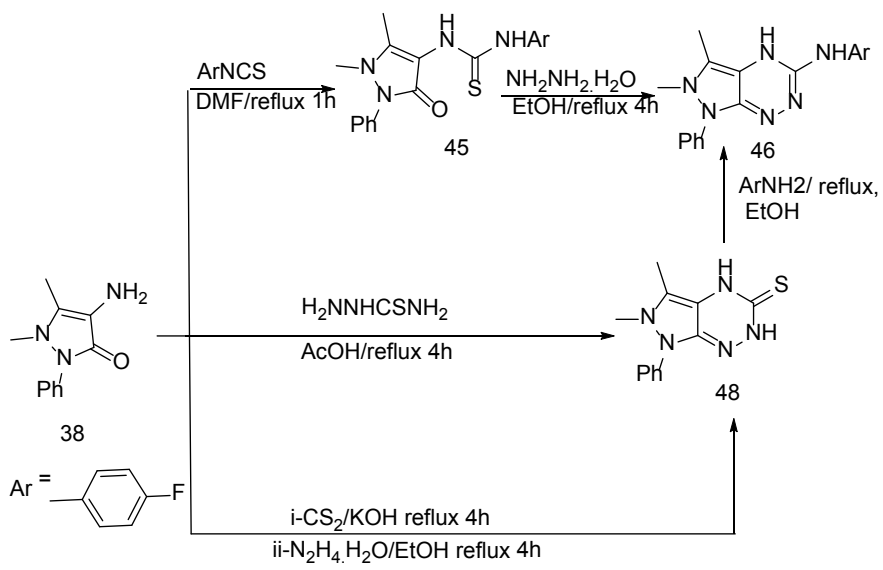

Scheme 17. Formation of compounds 45, 46 and 48 from 38.

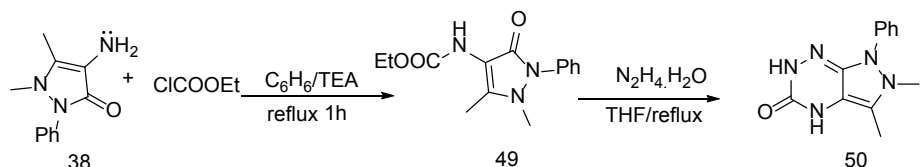

Scheme 18. Formation of compounds 49 and 50.

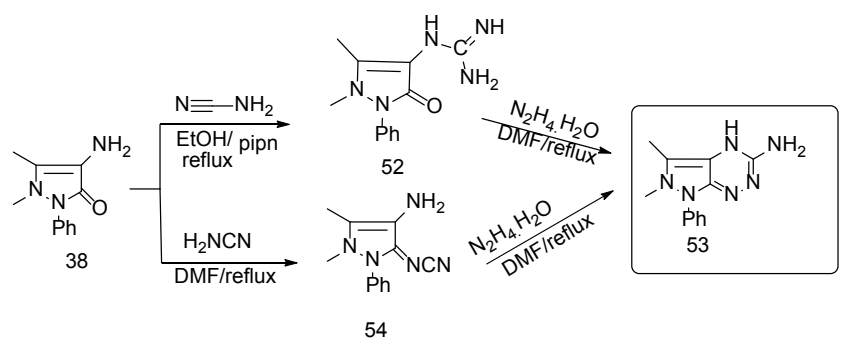

Scheme 19. Formation of compounds 52-54. 


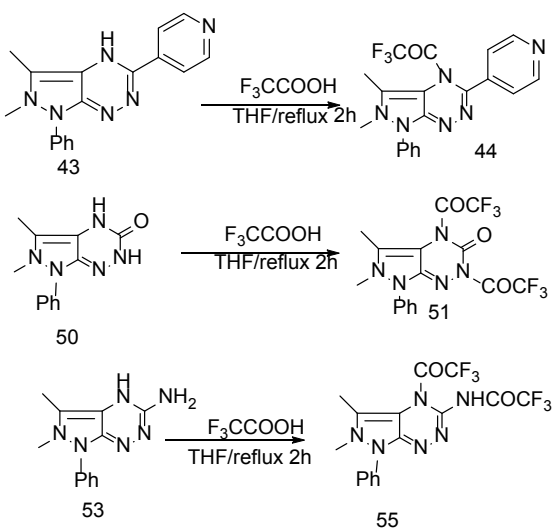

Scheme 20. Formation of compounds 44,51 and 55.

The enzymatic properties of the synthesized compounds 40-55 were evaluated against purine metabolic enzymes at concentrations of 30 - $500 \mu \mathrm{M}$ [26] [27]. The hexafluoroacetyl derivatives $\mathbf{5 1}$ and $\mathbf{5 5}$ were the strongest inhibitors with $\mathrm{IC}_{50}$ of $30-40 \mu \mathrm{m}$ followed by trifluoroacetyl 44 . Non-fluorinated derivatives exhibit much moderate to lethal inhibitor activity towards $E$. coli $P N P$ an enzyme [25].

\section{Synthesis and Reactivity of Fluorine Compounds Substituted Hetero-Polycyclic Nitrogen Systems Containing 1,2,4-Triazino-Indole Moiety (Condensed Skelton)}

Joshi et al. [28] reported some fluorine compounds containing 3-dialkyl aminoethyl thio-5-morpholino-methyl-1,2,4-triazino [5,6-b]indoles as having anti-bacterial, antifungal, and anti-viral activities (Figure 11). Also, Abdel-Rahman et al. [18] synthesized new fluorine substituted 3-amino-1,2,4-triazino-[5,6- $b$ indoles derived from sulfa-drugs and fluorinated reagents as photochemical probes agents for inhibition of vitiligo disease. On other hand, novel herbicidal 3-dimethylamino-4H-1,2,4-triazino [5,6- $b$ ] indoles obtained by Mizutani et al. [29] (Figure 11) [30] [31] [32]. Recently, fluorine substituted 3-amino-1,2,4triazino-indoles and/or 3-amino-imidazol-1,2,4-triazino-indoles have been used as anti-inflammatory agents [30] [31].

3-Amino-8-fluoro-5 $H$-1,2,4-triazino [5,6-b] indole (56) [30] (Scheme 21), was used to obtain a various of new fluorine compounds 57-61 via the treatment of 56 with different electrophilic reagents in various media. Thus, acylation of 56 by warming with glacial $\mathrm{AcOH}$ for short time yielded 3- $\mathrm{N}$-acylamino-derivative 57, while aroylation of $\mathbf{5 6}$ via warming with 3,5-dinitrobenzoyl chloride in DMF produced the benzamido derivative 58. Refluxing 56 with $\mathrm{PPh}_{3}$ (similarly as Wittigs reaction) afforded the phosphiimino-derivative 59 (Scheme 21).

Most of alkylated amino-1,2,4-triazino [5,6-b] indoles obtained exhibit a wide range of biological activities [31] [32]. Similarly, treatment of compound 56 with MeI (1\%aq.KOH. stiring at R.T), monochloroacetic acid (DMF), or chloroaceto- 
nitrile (DMF) lead to the direct formation of 3-N-alkyl derivatives 60-62 (Scheme 22) [30].

Thiazolidin-4-one derivatives obtained exhibit a highly biological, pharma-cological, and medicinal activities [33] [35]. Thus, condensation of compound 56 with 4-chlorobenzaldehyde in $\mathrm{AcOH}$ under refluxing yield the Schiff base 63, which upon cycloaddition with thiolactic acid in refluxing 1,4-dioxane, afforded 2,3,5-trisubstituted thiazolidine-4-one (46) (Scheme 23) [30]. The formation of 64 is shown in Figure 12.

The former structure of 64 deduced from the correct elemental analysis and spectral measurements. The mass fragmentation pattern of 64 gives us a good indication about that stability Figure 13 [30].
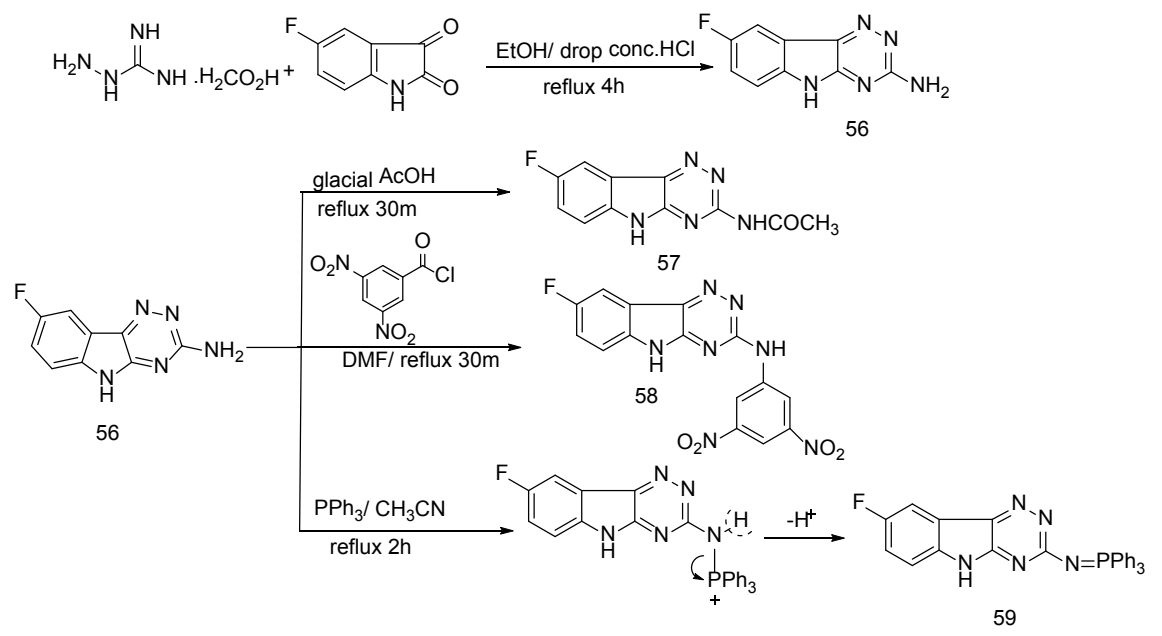

Scheme 21. Formation of compounds 57, 58 and 59.

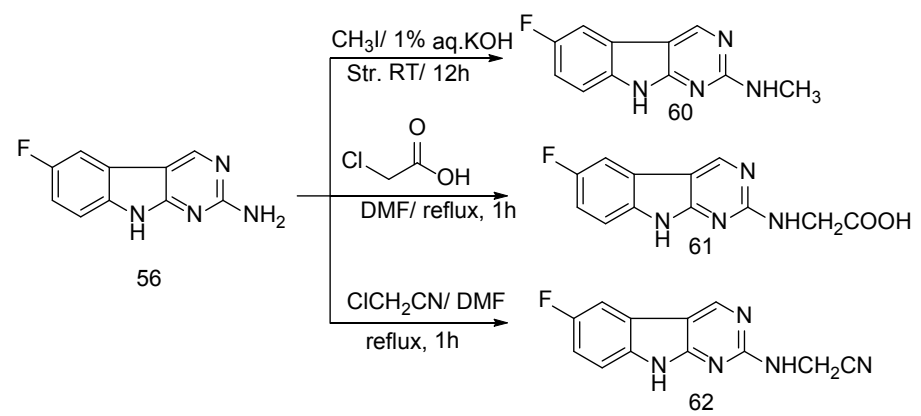

Scheme 22. Formation of compounds 60-62.

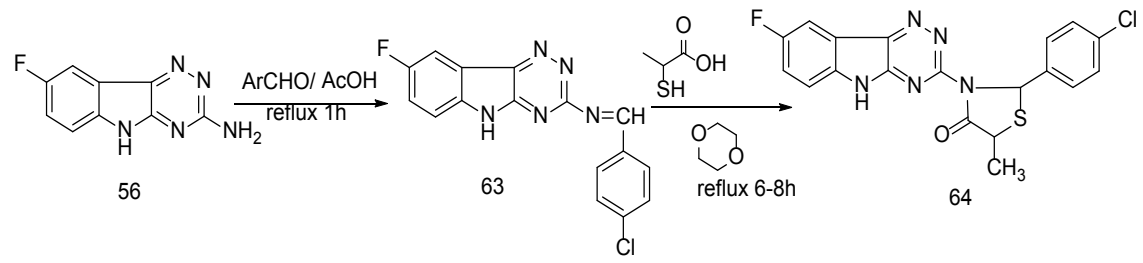

Scheme 23. Formation of compounds 63 and 64. 


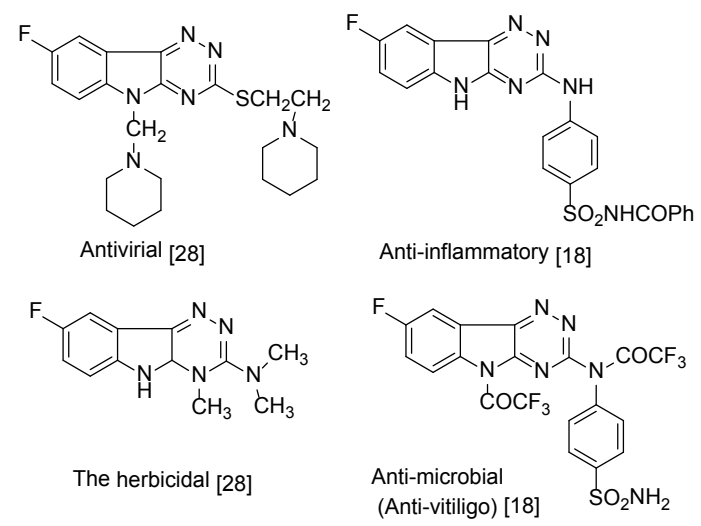

Figure 11. Some important medicinal compounds.

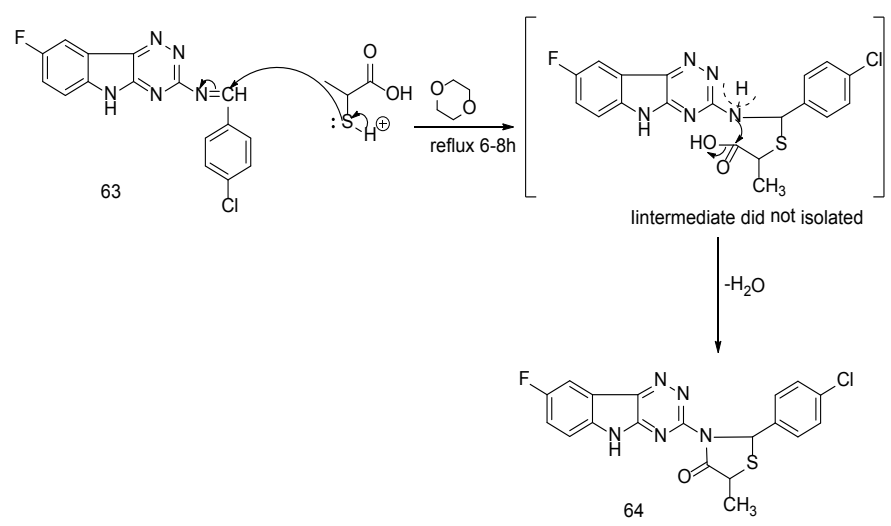

Figure 12. Formation of compound 64 from 63.

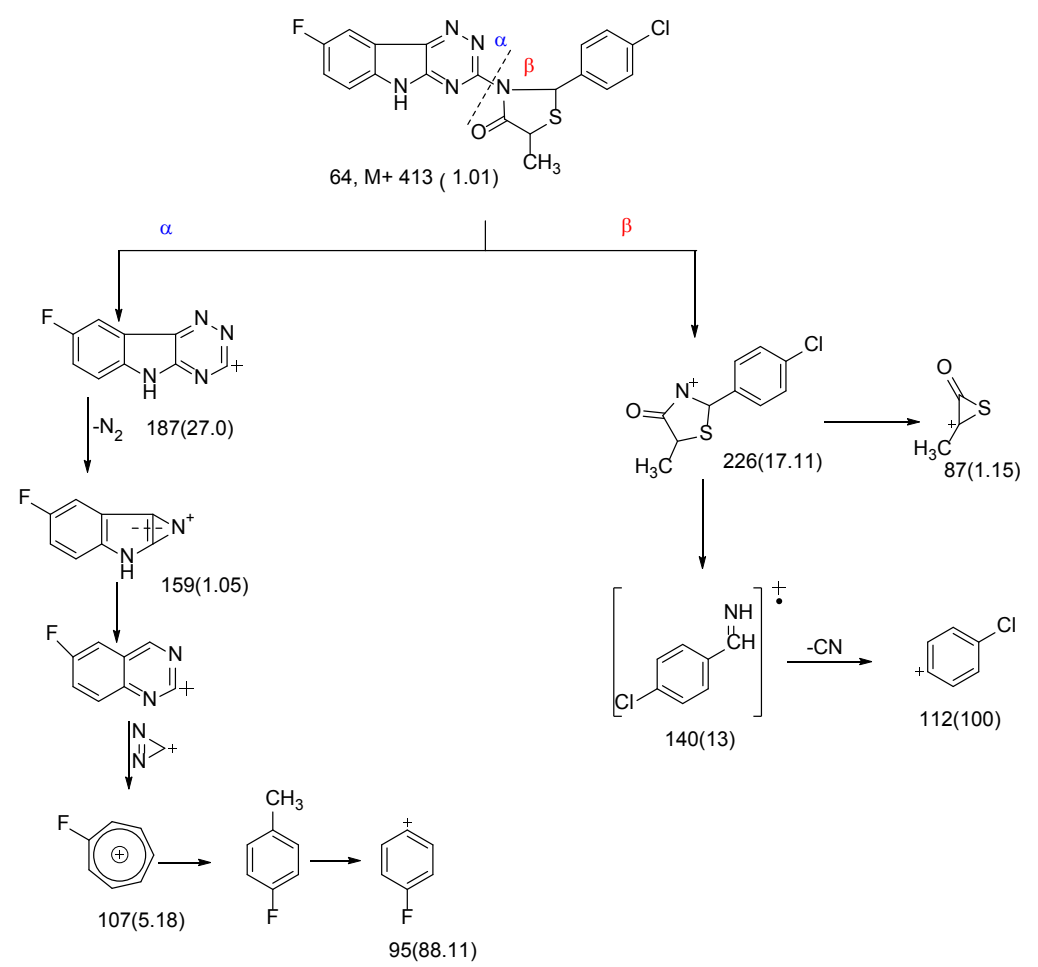

Figure 13. Mass fragmentation pattern of 64 . 
It is interesting that the interaction between 3-amino-8-fluoro-5H-1,2,4triazino $[5,6-b]$ indole (56) and chloroacetonitrile in refluxing DMF lead to the direct formation of 3-amino-7-fluoro-10H-imidazo [3,2-b] [1,2,4]triazino [5,6-b]indole (65) (Scheme 24) [30]. Formation of 65 may be a simple nuclophilic attack of $\mathrm{NH}_{2}$ to more $\mathrm{E}^{+}$center followed by cycloaddition reaction (Figure 14) [30]. Similarly, acylation and aroylation of compound 65 under the normal condition ( $\mathrm{RCOOH}$ and ArCOX) produced the 3-N-acyl/aroyl amino-imidazo [3,2-b] [1,2,4]triazino [5,6-b]indoles 66 and 67, respectively (Scheme 24) [30].

Finally, alkylation of 65 via treatment with $\mathrm{MeI}$ in aq. $\mathrm{KOH}$ at room temperature and/ or with chloroacetic acid in refluxing DMF yielded 3-N-alkylaminoderavitives 68 and 69, respectively (Scheme 25). Decarboxylation of 69 by warming with aq. $\mathrm{KOH}$ gave 3-methylamino-imidazo [3,2-b]-1,2,4-triazino [5,6-b]indole (68). The reaction of 65 with $\mathrm{PPh}_{3}$ in $\mathrm{CH}_{3} \mathrm{CN}$ yielded the phosphiimino 70 derivative (Scheme 25) [30]. The formation of compound 70 is indicate in Figure 15 [30].

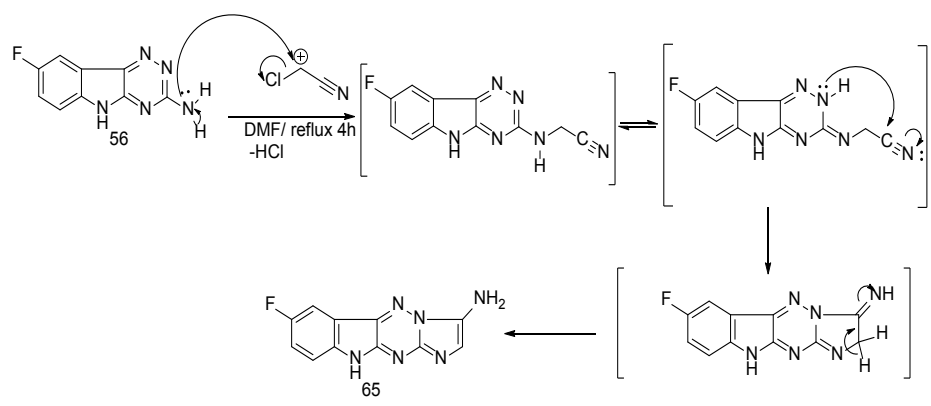

Figure 14. Formation of compound 65 from 56.

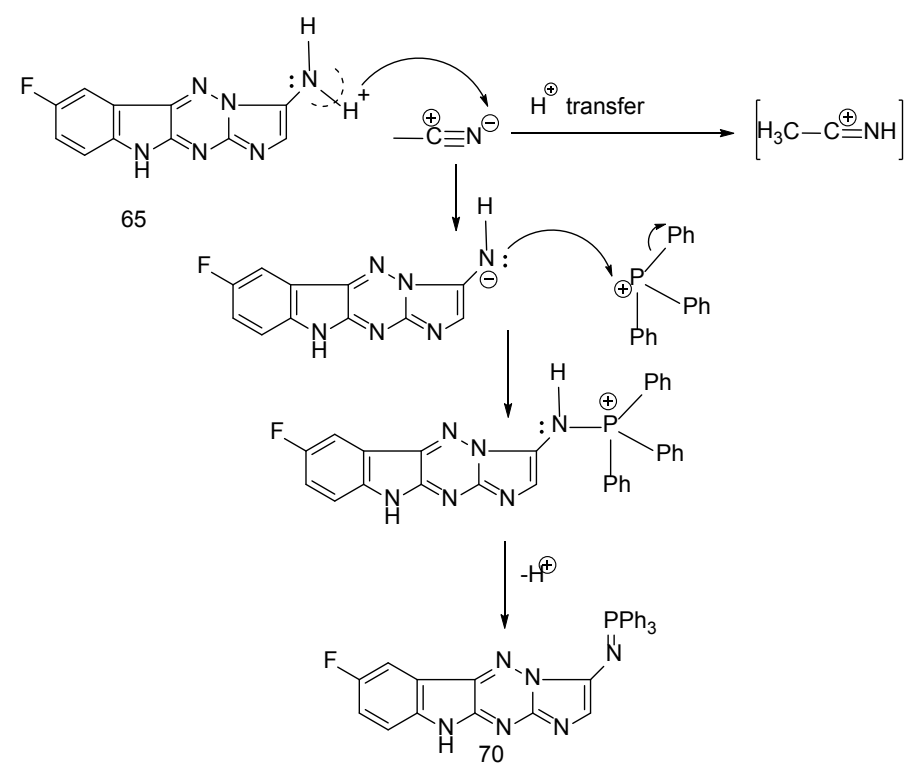

Figure 15. A possible route to formation of compound 70 from reaction of 65 with $\mathrm{PPh}_{3}$ in $\mathrm{CH}_{3} \mathrm{CN}$. 


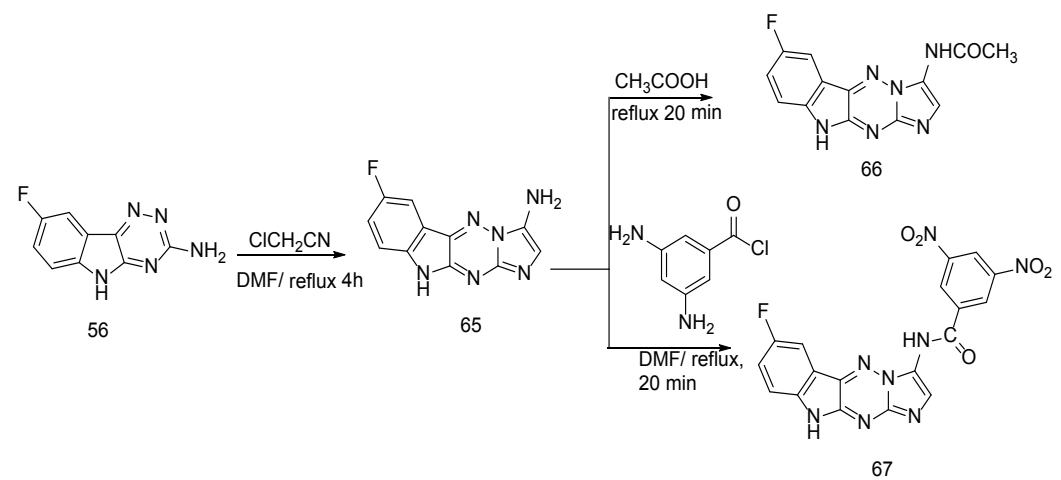

Scheme 24. Formation of compounds 66 and 67.

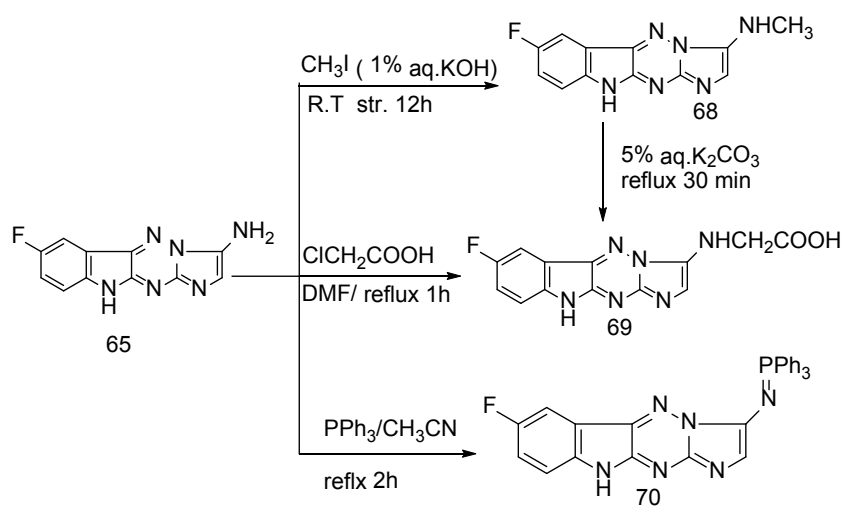

Scheme 25. Formation of compounds 68-70.

The introduction of fluorine atoms to 1,2,4-triazine derivatives often enhance and improve those properties, especially the medicinal and pharmacological field [1] [31]-[36]. Recently, the high resistance of microbes towards most drugs and antibiotics, is driving an urgent need for the synthesis of new highly bioactive systems in view of control on these resistant [37] [38] [39]. Thus, all synthesized fluorine compounds 56-69 evaluated as anti-inflammatory agents by using the standard indomethacin drug as standards, according the reported method [30], the activities were ranked as $65>56>64>>58>67>60$. Both the compounds 56 and 65 which contains a fluorine atom and an amino-group at the end of presence systems form a type of bio-conjugated systems. Also, a higher activity of compound $\mathbf{6 4}$ may be the formation of type combination between the thiazolidine-4-ones, and fluorine, chlorine bonded the terminal of systems [30].

\section{Important and Applications}

Fluorine containing 1,2,4-triazine moieties are high biological activity. Thus, the introduction of fluorine atoms to isolated, fused, and condensed 1,2,4-triazine systems can produce new bioactive targets depend on the position and magnitudes of total change. Most fluorinated 3-amino- or 3,5-diamino-6-aryl-1,2,4triazines exhibit an anti-inflammatory activity exceeding that of lamotrigine drug as Figure 16 [40]. 


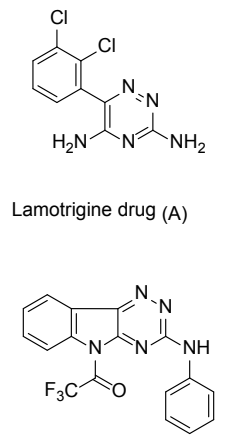

(D)

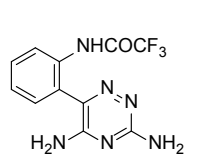

(B)

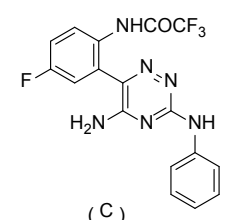

( C)

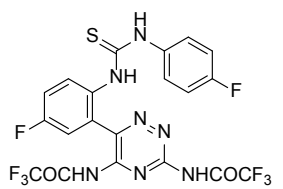

( E )

Figure 16. Some important medicinal compounds.

Most of fluorinated 1,2,4-triazin-5-one moieties display anti-HIV activity [1] [5]. Also, some fluorine-substituted with phosphorphous-1,2,4-triazines exhibited an important antioxidant activity [8]. As well as mostly, fluorine substituted 3-thioxo-1,2,4-triazinones showed a potential inhibitor as cyclin depend kinas (CDK2) for tumor cell damage [5] [6]. Recently, some fluorinated fused and isolated 1,2,4-triazines systems have been reported to have biocidal affect as molluscicidal agents against some snails [24]. In addition, many new fluorine compounds substituted by some or more heterobicyclic moieties, especially 1,2,4-triazine moiety, showed a wide range of antimicrobial activity [1] [7] [9] [10] [16] [18] [33]. Finally, some fluorinated 1,2,4-triazinones synthesized use as enzymatic affects towered some fungi [2] [9] [13] [16] [25].

\section{Conclusion}

A series of various fluorine compounds substituted with 1,2,4-triazine moieties have been developed by various routes. The results of these targets were characterized physically, chemically, or both, together with evaluations of the pharmacological activities. The introduction of fluorine atoms to heterocyclic nitrogen systems mostly enhances and improves the physical, chemical, and biological properties. In view of the fluorinated 1,2,4-triazine derivatives obtained, most have potentially beneficial applications for our life to treat various diseases such as anti-inflammatory, antimicrobial, or anti-HIV1 agents, or as cyclin dependent kinase inhibitors for tumor cell damage of DNA moiety. Hopefully, the present overview contributes an explanation of how new fluorine compounds bearing 1,2,4-triazine moieties and the related hetero-polycyclic nitrogen systems are formed and used.

\section{Conflicts of Interest}

The authors declare no conflicts of interest regarding the publication of this paper.

\section{References}

[1] Abdel-Rahman, R.M., Makki, M.S. and Al-Romaizan, A.N. (2014) Synthesis of 
Novel Fluorine Substituted Isolated and Fused Heterobicyclic Nitrogen Systems Bearing 6-(2'-Phosphorylanilido)-1, 2, 4-Triazin-5-One Moiety as Potential Inhibitor towards HIV-1 Activity. International Journal of Organic Chemistry, 4, 247. https://doi.org/10.4236/ijoc.2014.44028

[2] Bakhotmah, D. and Abdel-Rahman, R. (2017) Synthesis and Structural Determination of Novel Fluorinated Steroidal Spiro (Pyrazolo [4, 3-e] [1, 2, 4] Triazin-3'-yl) Derivatives as Affecting Enzymatic Agents. Letters in Organic Chemistry, 14, 134-140. https://doi.org/10.2174/1570178614666161230143228

[3] Abdel-Rahman, R. (1992) Synthesis of Some New Fluorine Bearing Trisubstituted 3-Thioxo-1, 2, 4-Triazin-5-Ones as Potential Anticancer Agents. Farmaco, 47, 319-326.

[4] Makki, M.S., Abdel-Rahman, R.M. and Alharbi, A.S. (2019) Synthesis and Anti-Inflammatory Effect of Some More New Fluorinated 3-Substituted Amino/3, 5-Diamino-1, 2, 4-Triazine Derivatives as Lamotrigine Analogs. Current Organic Synthesis, 16, 165-172. https://doi.org/10.2174/1570179415666181105142247

[5] Makki, M.S., Abdel-Rahman, R.M. and Khan, K.A. (2014) Fluorine Substituted 1, 2, 4-triazinones as Potential anti-HIV-1 and CDK2 Inhibitors. Journal of Chemistry, 2014, Article ID: 430573. https://doi.org/10.1155/2014/430573

[6] Makki, M.S.T., Abdel-Rahman, R.M. and Aqlan, F.M. (2015) Synthesis of Fluorinated Heterobicyclic Nitrogen Systems Containing 1, 2, 4-Triazine Moiety as CDK2 Inhibition Agents. International Journal of Organic Chemistry, 5, 200. https://doi.org/10.4236/ijoc.2015.53020

[7] Bawazir, W.A. and Abdel-Rahman, R.M. (2018) Synthesis of New Fluorinated Amino-Heterocyclic Compounds Bearing 6-Aryl-5-Oxo-1, 2, 4-Triazin-3-Yl Moiety as Antimicrobial Agents. International Journal of Organic Chemistry, 8, 349. https://doi.org/10.4236/ijoc.2018.84027

[8] Makki, M.S.T., Abdel-Rahman, R.M. and Alharbi, A.S. (2018) Synthetic Approach for Novel Fluorine Substituted a -Aminophosphonic Acids Containing 1,2,4-Triazin-5-One Moiety as Antioxidant Agents. IJOC International Journal of Organic Chemistry, 8, 1-15. https://doi.org/10.4236/ijoc.2018.81001

[9] Makki, M.S.T., Rahman, R.M.A. and Ali, O.A.A. (2016) Synthetic Approach for Novel Fluorine Substituted Thiadiazaphosphole Fused 1, 2, 4-Triazinopyridiazine Moieties as Bactericidal Agents. Asian Journal of Chemistry, 28, 917. https://doi.org/10.14233/ajchem.2016.19555

[10] Assiri, M.A., Abdel-Kariem, S.M., Ali, T.E. and Yahia, I.S. (2018) A Convenient Route to Novel Fluorinated 1,2,4,3-Triazaphospholo [1,5-a]Pyridines and Pyrido [1,2-b] [1,2,4,5]Triazaphosphinines. Arkivoc, 2018, 240-253. https://doi.org/10.24820/ark.5550190.p010.478

[11] Musatov, D., Kurilov, D. and Rakishev, A. (2008) Efficient Synthesis of 3-Amino-5, 6-Diphenyl-1, 2, 4-Triazine.

[12] Pandeya, S.N., et al. (2010) Synthesis and Biological Evaluation of Triazine Derivatives. Der Pharma Chemica, 2, 257-266.

[13] Taib, L.A. and Adibani, S.A. (2018) Synthesis of New Fluorinated Fused Heteropolycyclic Nitrogen Systems Containing a Pyrazolotriazine Moiety as Antimicrobial Agents Part I. International Journal of Organic Chemistry, 8, 176. https://doi.org/10.4236/ijoc.2018.81013

[14] Krystof, V., et al. (2006) 4-Arylazo-3,5-Diamino-1H-Pyrazole CDK Inhibitors: SAR Study, Crystal Structure in Complex with CDK2, Selectivity, and Cellular Effects. Journal of Medicinal Chemistry, 49, 6500-6509. 
https://doi.org/10.1021/jm0605740

[15] Gucký, T., et al. (2010) Synthesis and Anticancer Activity of Some 1, 5-Diaryl-3-(3, 4, 5-Trihydroxyphenyl)-1H-Pyrazolo [4, 3-e] [1, 2, 4] Triazines. Monatshefte für Chemie-Chemical Monthly, 141, 709-714. https://doi.org/10.1007/s00706-010-0314-4

[16] Aqlan, F.M., Makki, M.S. and Abdel-Rahman, R.M. (2016) Synthesis, Spectroscopic Studies of Fluorinated Pyrimido-1, 2, 4-Triazines: Protective Effect against Some Plant Pathogenic Fungi. Journal of Heterocyclic Chemistry, 53, 1310-1317. https://doi.org/10.1002/jhet.2386

[17] Ali, T.E. and Abdel-Rahman, R.M. (2014) Synthesis and Antioxidant Activities of Some Novel Fluorinated Spiro [Oxindole-Thiazolidine] Fused with Sulfur and Phosphorus Heterocycles. Journal of Sulfur Chemistry, 35, 399-411. https://doi.org/10.1080/17415993.2014.896363

[18] Abdel-Rahman, R.M., Makki, M.S.I. and Bawazir, W.A. (2011) Synthesis of Some More Fluorine Heterocyclic Nitrogen Systems Derived from Sulfa Drugs as Photochemical Probe Agents for Inhibition of Vitiligo Disease-Part I. Journal of Chemistry, 8, 405-414. https://doi.org/10.1155/2011/586063

[19] Al-romaizan, A.N. (2019) Behavior of 3-Hydrazino-6-Aryl-1,2,4-Triazin-5-One as a Strong Nucleophile towards Active Electrophilic Compounds and Their Antibacterial Evaluation. Mediterranean Journal of Chemistry, 9, 279-257. https://doi.org/10.13171/mjc93191014920aar

[20] Abdel-Rahman, R.M. and Abdel-Monem, W.R. (2007) Chemical Reactivity of 3-Hydrazino-5,6-diphenyl-1,2,4-triazine (I) Towards $\pi$-Acceptors Activated Carbonitriles. ChemInform, 38. https://doi.org/10.1002/chin.200737157

[21] Chamberlain, K. and Carter, G.A. (1980) The Fungitoxicity of Substituted 2-Phenylbenzofurans. Pesticide Science, 11, 526-532. https://doi.org/10.1002/ps.2780110510

[22] Finney, D.J. (1952) Probit Analysis: A Statistical Treatment of the Sigmoid Response Curve. Cambridge University Press, Cambridge.

[23] McCornack, A.A. and Eldon Brown, G. (1967) Proceedings of the Florida State Horticultural Society. Florida State Horticultural Society, Lake Alfred, FL, 225.

[24] Abdel-Rahman, R.M., et al. (2019) Design, Synthesis and Molluscicidal Activity of New Phosphorus Compounds Bearing Fluorine Substituted 1,2,4-Triazolo [3,2-c] [1,2,4]Triazine Derivatives. Letters in Organic Chemistry, 17, 184-190. https://doi.org/10.2174/1570178616666190718120953

[25] Abdel-Rahman, R.M., Angawi, R.F. and Al-Mehmadi, A.R. (2017) Synthesis and Biological Evaluation of Fluorine Substituted Pyrazolo [4, 3-e] [1, 2, 4] Triazines as Purine Analogues. Journal of Saudi Chemical Society, 21, 495-503. https://doi.org/10.1016/j.jscs.2016.11.004

[26] Kulikowska, E., Bzowska, A., Wierzchowski, J. and Shugar, D. (1986) Properties of Two Unusual, and Fluorescent, Substrates of Purine-Nucleoside Phosphorylase: 7-Methylguanosine and 7-Methylinosine. Biochimica et Biophysica Acta (BBA)Protein Structure and Molecular Enzymology, 874, 355-363. https://doi.org/10.1016/0167-4838(86)90035-X

[27] Borges, F., Fernandes, E. and Roleira, F. (2002) Progress towards the Discovery of Xanthine Oxidase Inhibitors. Current Medicinal Chemistry, 9, 195-217. https://doi.org/10.2174/0929867023371229

[28] Joshi, K.C., Pathak, V.N. and Jain, S.K. (1981) Synthesis and Antibacterial Activity 
of Some New Fluorine Containing 3-Arylthiazolo [3,2:2',3']-1,2,4-Triazino [5',6'-b] Indoles. Journal für Praktische Chemie, 323, 159-163. https://doi.org/10.1002/prac.19813230122

[29] Mizutani, M., Yoshida, R. and Sanemitsu, Y. (1987) Novel Herbicidal Compounds, 3-Dimethylamino-4H-[1,2,4]-Triazino [5,6-b] Indoles. Agricultural and Biological Chemistry, 51, 3177-3178. https://doi.org/10.1271/bbb1961.51.3177

[30] Bawazir, W.A. and Alnajjarm D.K. (2020) Synthesis of New Fluorinated 3-Substituted Amino-5H-8-Fluoro-1,2,4-Triazino [5,6-b]Indoles and 3-Substituted Amino-9H-7-Fluoro-Imidazo [3,2-b] [1,2,4]Triazino [5,6-b]Indoles as Antimicrobial Agents.

[31] Bawazir, W.A. and Alnajjar, D.K. (2019) Synthesis of N2 and S-Alkyl of 8-Nitro-2H-[1,2,4]Triazino-[5,6-b]Indole-3(SH)-Thione as Antibacterial Probes. Indian Journal of Heterocyclic Chemistry, 29.

[32] Monge, A., et al. (1991) New 5H-1,2,4-Triazino [5,6-b]Indole and Aminoindole Derivatives. Synthesis and Studies as Inhibitors of Blood Platelet Aggregation, Anti-Hypertensive agents and Thromboxane Synthetase Inhibitors. European Journal of Medicinal Chemistry, 26, 179-188. https://doi.org/10.1016/0223-5234(91)90027-K

[33] Taib, L.A. (2018) Synthesis and Antifungal Activity of Some New Fluorine-Substituted 4-Thiazolidinone Bearing 1,2,4-Triazinone. IJOC International Journal of Organic Chemistry, 8, 170-175. https://doi.org/10.4236/ijoc.2018.81012

[34] Srikanth Kumar, K., Lakshmana Rao, A. and Basaveswara Rao, M.V. (2018) Design, Synthesis, Biological Evaluation and Molecular Docking Studies of Novel 3-Substituted-5-[(Indol-3-yl)methylene]-Thiazolidine-2,4-Dione Derivatives. $\mathrm{He}$ liyon, 4, e00807. https://doi.org/10.1016/j.heliyon.2018.e00807

[35] Abdel-Rahman, R.M.A., Alharbi, A.S. and Alshammari, N.A. (2019) Synthesis of Novel 4-Thiazolidinone and Bis-Thiazalidin-4-One Derivatives Derived from 4-Amino-Antipyrine and Evaluated as Inhibition of Purine Metabolism Enzymes by Bacteria. International Journal of Organic Chemistry, 9, 85. https://doi.org/10.4236/ijoc.2019.92008

[36] Abdel-Rahman, R.M. (1999) Synthesis and Chemistry of Fluorine Containing Bioactive 1,2,4-Triazines-An Overview. Chemistry of Uncondensed 1,2,4-Triazines, Part III. Pharmazie, 54, 791-803.

[37] Abdel-Rahman, R.M. (2001) Role of Uncondensed 1,2,4-Triazine Compounds and Related Heterobicyclic Systems as Therapeutic Agents-A Review. Pharmazie, 56, 18-22. https://doi.org/10.1002/chin.200116291

[38] Abdel-Rahman, R.M. (2001) Role of Uncondensed 1,2,4-Triazine Derivatives as Biocidal Plant Protection Agents-A Review. Die Pharmazie, 56, 195-204.

[39] Makki, M.S.T., Rahman, R.M.A. and Ali, O.A.A. (2015) Synthesis of New Fluorinated 1,2,4-Triazino [3,4-b] [1,3,4]Thiadiazolones as Antiviral Probes-Part II-Reactivities of Fluorinated 3-Aminophenyl-1,2,4-Triazinothiadiazolone. IJOC International Journal of Organic Chemistry, 5, 153-165. https://doi.org/10.4236/ijoc.2015.53017

[40] Winter, C.A., Risley, E.A. and Nuss, G.W. (1962) Carrageenin-Induced Edema in Hind Paw of the Rat as an Assay for Antiinflammatory Drugs. Proceedings of the Society for Experimental Biology and Medicine, 111, 544-547. https://doi.org/10.3181/00379727-111-27849 